\title{
The Austenite Grain Growth Behavior and Mathematical Model of 20CrMnTiH
}

\author{
Feng WANG ${ }^{1, a}$; Wei FENG ${ }^{1,2, b,{ }^{*}} ;$ Zhi-Xing GUAN $^{1, c} ;$ Ri-Jie CONG ${ }^{1, d} ;$ FeiQIN $^{1, e}$ \\ ${ }^{1}$ School of Materials Science and Engineering, WuhanUniversity of Technology, Wuhan 430070, \\ China. \\ 2.Hubei Key Laboratory of Advanced Technology of Automotive Parts, Wuhan 430070, China. \\ a944050743@qq.com, bfengwei@whut.edu.cn, ' $1320675553 @ q q . c o m,{ }^{d} 1791946545 @ q q . c o m,{ }^{e} 1$ \\ 308806259@qq.com \\ ${ }^{*}$ Corresponding author : Wei Feng
}

Keywords: $20 \mathrm{CrMnTiH}$ steel, Heating temperature, Holding time, Austenite grain growth.

\begin{abstract}
The $20 \mathrm{CrMnTiH}$ gear steel was heated at temperature range from $850^{\circ} \mathrm{C}$ to $1250^{\circ} \mathrm{C}$ and at holding time range from 0 s to 480 s to obtain the law of austenite grain growth by using Gleeble-3500 thermo-simulation-machine in this research. The effects of heating temperature and holding time on austenite grain growth behavior were investigated. The results show that austenite grain size increased with the increase of heating temperature and the extension of holding time. By introducing the Sellars model, the austenite grain growth model was developed based on the analysis of experiment data. According to the comparison of calculated values with experiment values, the calculated results are in good agreement with the experimental results.
\end{abstract}

\section{Introduction}

20CrMnTiH is a kind of good carburizing alloy steel, which occupies a dominant position of transmission parts in China, and is widely used to manufacture important mechanical parts which needs to bear high stress and impact load, such as gear box, clutch gear, etc.[1]. With the rapidly development of industry, gear steel with higher strength and hardness is put forward to meet the demand of anti-impact and wear resistance.

Many scholars researched the properties of $20 \mathrm{CrMnTiH}$ in China. Liu analyzed the influences of main forging parameters on the flow stress of $20 \mathrm{CrMnTiH}$ steel by taking flow stress as an objective function, and obtained the mathematical models for flow stress based on statistical analysis [2]. Chai proposed a modifiedZerilli-Armstrong (ZA) model based upon the original ZA model and Johnson-Cook model to describe the flow stress of 20CrMnTiH steel under different deformation conditions [3].Wu obtained the true stress-true strain curves and built the mathematical models using a modified Zener-Hollomon parameter considering the compensation of strain rate based on Arrhenius equation by analyzing the experimental data of 20CrMnTiH steel [4]. Feng established the flow stress and the dynamic recrystallization model of $20 \mathrm{CrMnTiH}$, which proved that higher temperature and lower strain rate were favorable to the increase of dynamic recrystallization of 20CrMnTiH based on the regression analysis of experimental data [5].

However, the existed mathematical models are mainly used to predict the flow stress of 20CrMnTiH steel, while the austenite grain growth behavior don't be research. Some researchers investigated the austenite grain growth behavior and they found that heating temperature, holding time are the main affecting factor on the austenite grain growth behavior [6-7]. Pous-Romero developed a model to show the evolution of the austenite grain structure in nuclear pressure vessel steel [8]. Lee investigated the effects of alloying elements on austenite grain growth and formulated an empirical equation to predict the austenite grain size of low alloy steel [9]. Kennett evaluated the effect of austenite grain size on dislocation density and microhardness in low-carbon Nb-Ti microalloyed lath martensite[10]. Yang confirmed that the austenite grain size affect the martensite-start temperature by new experimental evidence [11]. Heinze proposed that the austenite grain size not only affect the martensite transformation temperatures, but also affect the residual stress development during welding [12]. The microstructure of the material is decided by the 
composition of the metal material and process technologies, meanwhile the properties are primary determined by the metal internal microstructure. In the forging process, prone to austenite grain growth, according to the Hall-Petch theory, the smaller the average grain size of the material is, the higher hardnesswill be obtained, so the austenite grain growth has greater impact on materials mechanical properties [13].

In this study, to understand the effects of the process parameters such as heating temperature and holding time on the austenite grain size and to decide the process parameters during hot forging 20CrMnTiH steel components, theisothermal holding experiments were conducted to investigate the evolution of austenite grain of the $20 \mathrm{CrMnTiH}$ steel samples under different holding time and heating temperature, the mathematical model of austenite grain growth was formulated by dealing with the experiment data. So it's very helpful to optimize the process for hot precision forging gear parts of 20CrMnTiH steel by the evolution law of the microstructure during hot deformation.

\section{Experimental materials and methods}

The chemical composition (wt.\%) of the 20CrMnTiH steel in this study is $0.18 \mathrm{C}, 0.29 \mathrm{Si}, 1.09 \mathrm{Mn}$, $0.015 \mathrm{P}, 0.017 \mathrm{~S}, 1.18 \mathrm{Cr}, 0.076 \mathrm{Cu}, 0.062 \mathrm{Ti}$. The cylindrical specimens were chosen with the diameter of $8 \mathrm{~mm}$ and the height of $12 \mathrm{~mm}$.

20CrMnTiH steel samples were put into the Gleeble-3500 thermo-simulation-machine and first heated at the rate of $10^{\circ} \mathrm{C} / \mathrm{s}$ to the austenitizing temperature of $850^{\circ} \mathrm{C}, 950^{\circ} \mathrm{C}, 1050^{\circ} \mathrm{C}, 1150^{\circ} \mathrm{C}$, and $1250^{\circ} \mathrm{C}$, respectively, and then held at the temperature for different time of $0 \mathrm{~s}, 120 \mathrm{~s}, 240 \mathrm{~s}, 360 \mathrm{~s}$, and 480s, respectively. Then these heat specimens were quenched into water immediately to preserve the high temperature microstructure. The austenite grain growth behavior will occur under the above austenitizing heat preservation temperature, and the evolution of austenite grain is closely related to the initial grain size, deformation temperature and heat preservation time.

After heating and heat preservation experiment was completed,the quenched specimens were sectioned along longitudinal section and inlaid with bakelite powder, then the inlaid specimen will be ground by metallographic sandpaper, and then polished with polishing machines and diamond polishing agent, next etched in a hot solution of saturated picric acid to reveal the austenite grain boundary. Finally, the microstructure metallographic pictures were obtained by optical microscope and the average grain sizes of different samples were measured using the linear intercept method according to ASTM standards.

\section{Experimental Results and Discussion}

The microstructure characterization under different heating temperature and holding time.Fig. 1 represents the microstructure of $20 \mathrm{CrMnTiH}$ steel under different holding time at $950^{\circ} \mathrm{C}$. As seen from Fig.1a, we can see that the grains are completeaustenitizing when the temperature is heated $950^{\circ} \mathrm{C}$. The austenite grain boundaries become flat when the holding time is over $240 \mathrm{~s}$ according to Fig.1b-e. The austenite grains become coarser with prolonging the holding time when the temperature is constant as shown from Fig.1. 

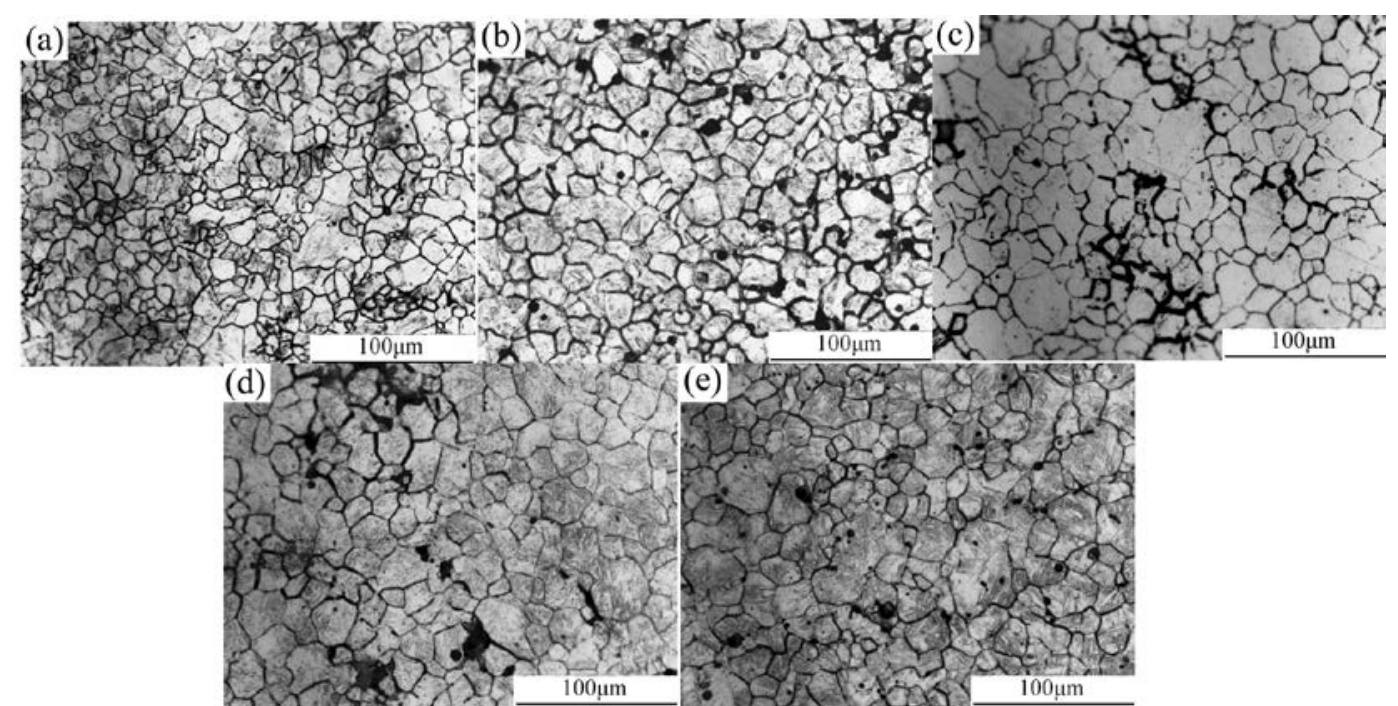

Fig.1 Microstructure of 20CrMnTiH steel under different holding time at $950^{\circ}$ C: (a) 0s; (b)120s;(c)240s;(d)360s;(e)480s

Fig.2 shows the microstructure of 20CrMnTiH steel under different heating temperature when the holding is 480s.As seen from fig.2a, we can see that the grains are completeaustenitizing and some small grains are obtained in the large grain boundaries when the temperature is heated $850^{\circ} \mathrm{C}$ and holding time is 480s. And we can also see that austenite grains become larger as the heating temperature rises according to fig.2b-e.

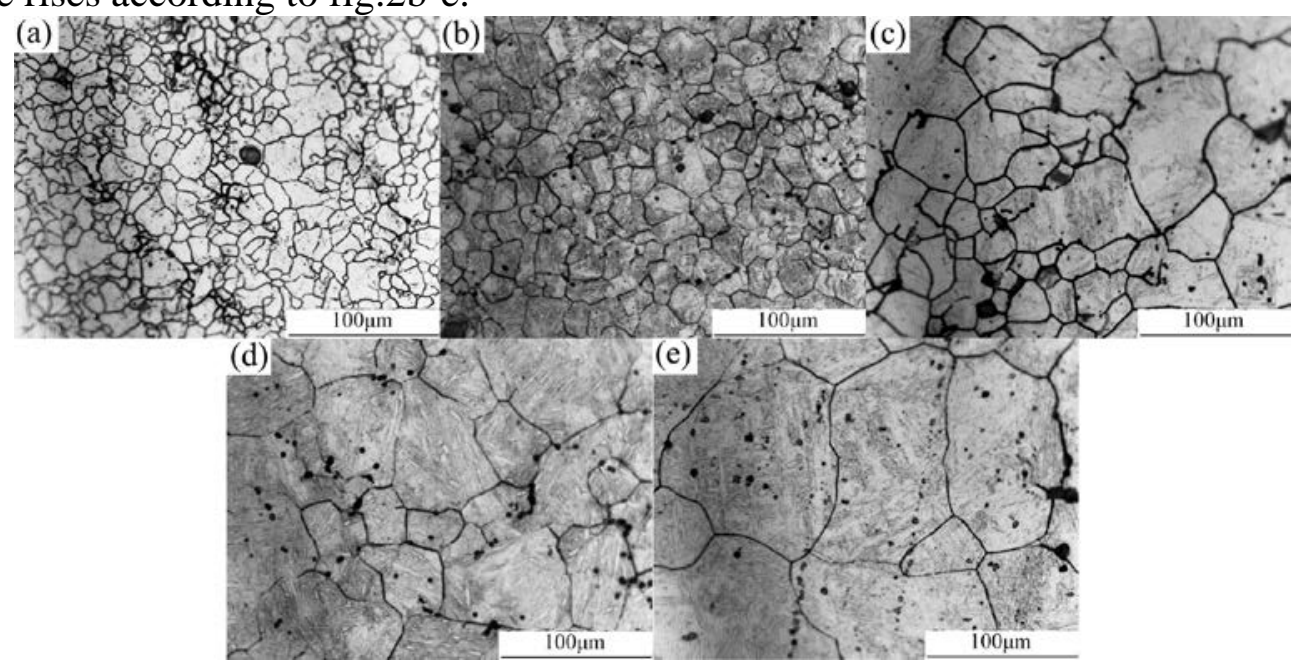

Fig.2 Microstructure of 20CrMnTiH steel for 480 s under different heating temperature:(a) $850^{\circ} \mathrm{C}$;

$$
\text { (b) } 950^{\circ} \mathrm{C} \text {; (c) } 1050^{\circ} \mathrm{C} \text {; (d) } 1150^{\circ} \mathrm{C} \text {; (e) } 1250^{\circ} \mathrm{C} \text {; }
$$

Fig.3 (a) shows effect of holding time on average austenite grain size at different heating temperature. From Fig.3 (a), we can observe that the austenite grain size is muchcoarser with extending holding time when the heating temperature is constant. And the growth feed is faster with extending holding time when the heating temperature is above $950^{\circ} \mathrm{C}$. Fig.3 (b) shows effect of heating temperature on average austenite grain size at different holding time. We can see that the austenite grain size is much coarser with increasing heating temperature when the holding time is constant, and the effects of the heating temperature on the austenite grain size growth are almost consistent whatever the holding time is. The reason may be the austenite is generated by nucleation and growth according to austenite grain growth kinetics during the hot working process of metal. The activation energy for grain boundary motion and nucleation increasesa with the increasing heating temperature, so the grain grows at a faster speed when the temperature rises. 


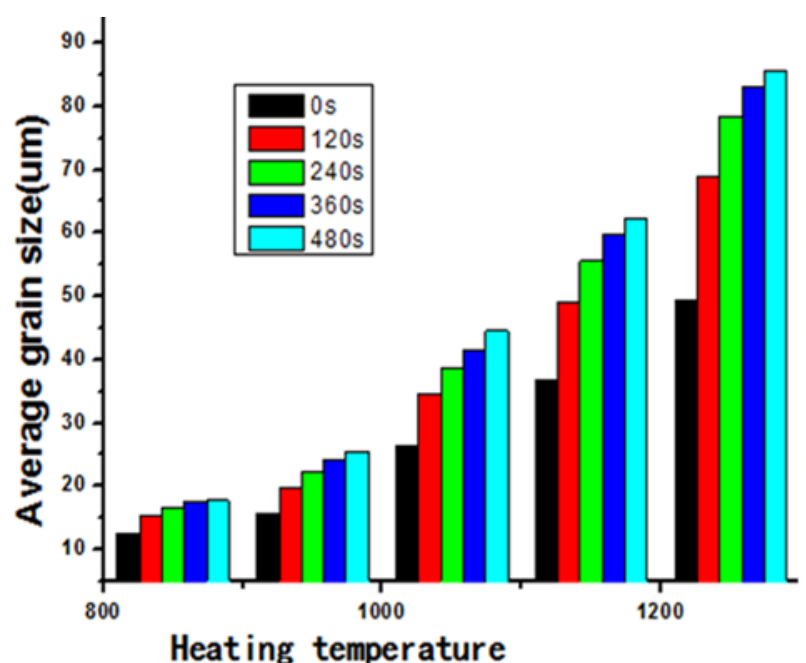

(a)

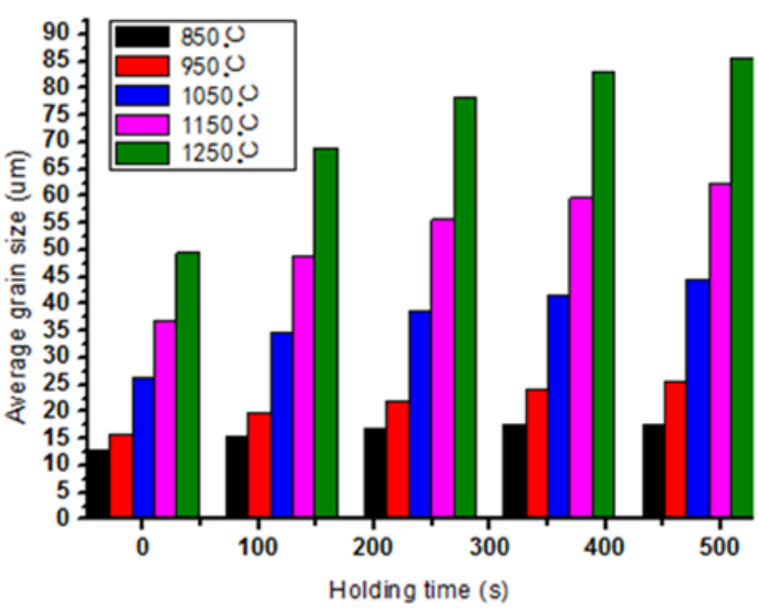

(b)

Fig.3 Effect of holding time and heating temperature on average grain size

The mathematical model of austenite grain growth.According to the analysis above, the heating temperature and holding time affect the austenite grain growth behavior together. In order to obtain the quantitative relationship among the grain size of austenite, the holding time and the heating temperature, the Sellars model of phenomenological theory that shown in Eq (1) can be used to describe the relationship [13].

$$
d_{g}^{m_{1}}=d_{0}^{m_{1}}+a_{1} t^{n_{1}} \exp \left(-Q_{g g} / R T\right)(1)
$$

where $d_{g}$ is thegrain size of austenite size [um], $d_{0}$ is the initial grain size [um], $Q_{g g}$ is the austenite grain growth activation energy $[\mathrm{kJ} / \mathrm{mol}], \mathrm{R}$ is the gas constant $\left[8.314 \mathrm{~J} /\left(\mathrm{mol}^{*} \mathrm{~K}\right)\right], T$ is the absolute temperature $[K], a_{1}, m_{1}, n_{1}$ are the material constant.

Taking the natural logarithm on both sides of Eq. (1):

$$
\ln \left(d_{g}^{m_{1}}-d_{0}^{m_{1}}\right)=\ln a_{1}+n_{1} \ln t+\left(-\frac{Q_{g g}}{R T}\right)(2)
$$

So it can be obtained that $n_{1}=\frac{\partial \ln \left(d_{g}^{m_{1}}-d_{0}^{m_{1}}\right)}{\partial \ln t}$ and $Q_{g g}=-R \frac{\partial \ln \left(d_{g}^{m_{1}}-d_{0}^{m_{1}}\right)}{\partial(1 / T)}$ according to Eq. (2). Then the values of $n_{1}$ and $Q_{g g}$ can be calculated from the slope of the lines in $\ln \left(d_{g}{ }^{m_{1}}-d_{0}{ }^{m_{1}}\right)-\ln t$ and $\ln \left(d_{g}^{m_{1}}-d_{0}^{m_{1}}\right)-1 / T$, respectively.

Meanwhile, the value of $m_{1}$ can be obtained at the range of 2-6. Taking $m_{1}=2$ as an example, the slope of $\ln \left(d_{g}{ }^{m_{1}}-d_{0}{ }^{m_{1}}\right)-\ln t$ and $\ln \left(d_{g}{ }^{m_{1}}-d_{0}{ }^{m_{1}}\right)-(1 / T)$ can be obtained based on the experiment data by the nonlinear regression method, and the values of $Q_{q q}$ and $n_{1}$ can be obtained under different heating temperature and holding time as shown in table 1 and table 2 , so it is $Q_{q q}=124951.6 \mathrm{~kJ} / \mathrm{mol}$, $n_{1}=0.626296$ by averaging the values, then the value of $a$ of can be calculated as 258842.8 according to the Eq. (1).

Table.1 The slope of $\ln \left(d_{g}{ }^{m_{1}}-d_{0}{ }^{m_{1}}\right)-\ln t$ at different temperatures

\begin{tabular}{ccccccc}
\hline Temperature $\left({ }^{\circ} \mathrm{C}\right)$ & 850 & 950 & 1050 & 1150 & 1250 & average \\
\hline Slope & 0.51756 & 0.76374 & 0.66412 & 0.63933 & 0.54673 & 0.626296 \\
\hline
\end{tabular}

Table.2 The slope of $\ln \left(d_{g}{ }^{m_{1}}-d_{0}{ }^{m_{1}}\right)-(1 / T)$ slope at different times

\begin{tabular}{cccccc}
\hline Time(s) & 120 & 240 & 360 & 480 & average \\
\hline Slope & -15040.8 & -15107.325 & -14901.821 & -15066.293 & 15029.061 \\
\hline
\end{tabular}


According to the calculated process above, the mathematical models of austenite grain growth can be obtained under different values of $m_{1}$ at $2,3,3.5,4,4.5,5,5.5,2.5,6$, meanwhile the standard deviation of the austenite grain size model under different $m_{1}$ values also can be obtained by the comparison of calculated values and measured values. The relationship curve of standard deviation and $m_{1}$ can be developed as shown in Fig.4, so the 5 order equation between $\mathrm{m} 1$ values and the standard deviation can be fitted by the Origin software as shown in Eq. (3).

$$
A S E=0.49952-0.25963 m_{1}+0.11998 m_{1}^{2}-0.02513 m_{1}^{3}+0.00075 m_{1}^{4}+0.00017 m_{1}^{5} \text { (3) }
$$

So the minimum value of $A S E$ can be obtained according to the 5 order equation, it is $m_{1}=5.268$.

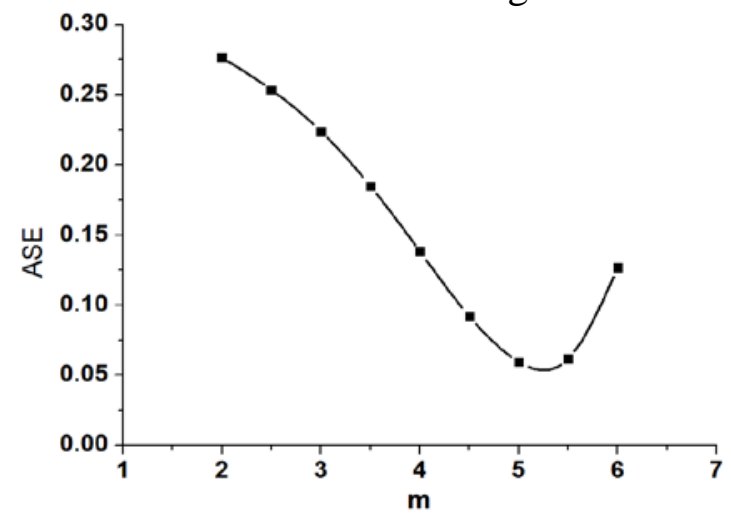

Fig.4 The ASE value of under different $m_{1}$ values

According to Fig.4, the minimum standard deviation can be acquired as the $\mathrm{m} 1$ is 5.268 . So the coefficient value of the austenite grain growth can be calculated, they aren=0.99758, $Q=$ $304852.4 \mathrm{~kJ} / \mathrm{moland} a_{1}=8.21 \mathrm{E}+17$. The austenite grain growth model of $20 \mathrm{CrMnTiH}$ under high temperature as follows:

$$
d_{g}^{5.268}=d_{0}^{5.268}+8.21 \times 10^{17} t^{0.99758} \times e^{(-304852.4 / R T)}
$$

The predicted values and the experimental values are compared under different conditions, as shown in Figure 5. The averagestandard deviation is $9.361 \%$, which shows the predicted values calculated by Eq.(4) agree well with the experimental values, so the austenite grain growth model of 20CrMnTiH is reliable.

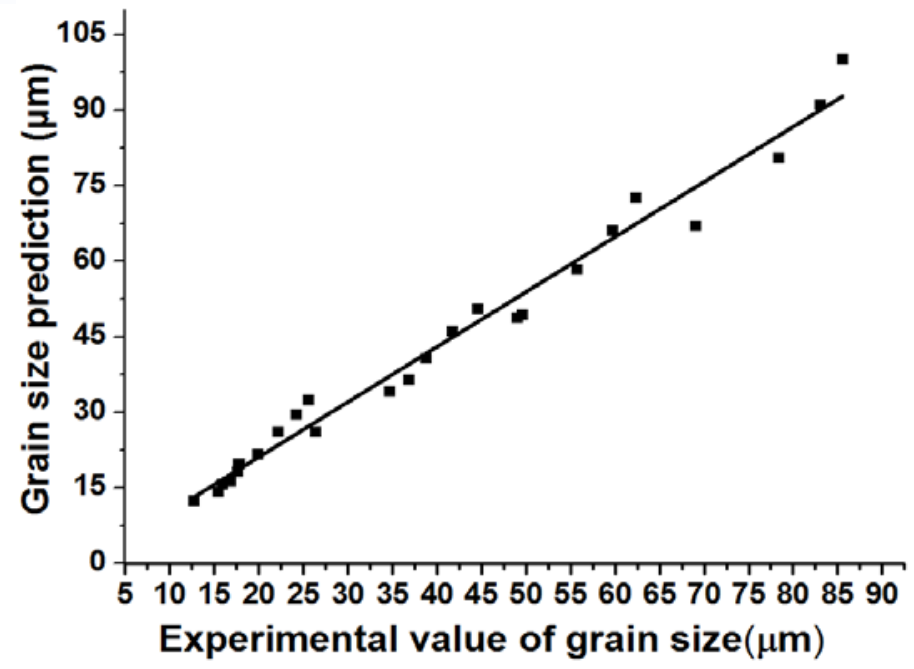

Fig.5 The comparison of calculated values with experiment values of austenite grain size

\section{Conclusions}

The heating and heat preservation tests of $20 \mathrm{CrMnTiH}$ steel were carried on the Gleeble-3500 thermo-simulation system in $850^{\circ} \mathrm{C} \sim 1250^{\circ} \mathrm{C}$, and the austenite microstructuremetallograph and grain size of the samples were observed. The following conclusions can be obtained: 
(1) The austenite grain growth behavior occurred in the heating and heat preservation experiment, and the austenite grain grows with the increase of heating temperature and holding time.

(2) The effect of heating temperature on austenite grain size is more significant than that of holding time.

(3) The mathematical model of austenite grain growth was formulated as: $d_{g}^{5.268}=d_{0}^{5.268}+8.21 \times 10^{17} t^{0.99758} \times e^{(-304852.4 / R T)}$, so the austenite grain size can be calculated under different heating temperature and holding time, which is agreement with the experiment data.

\section{Acknowledgements}

The Undergraduate Innovation and entrepreneurship training Program of Wuhan University of Technology (No. 20151049701004), the Natural Science Foundation of China (No. 51475344) and the Natural Science Foundation of Hubei Province (No. 2014CFB855) for the support given to this research.

\section{References}

[1] W.Feng, Y.H. Fu. High temperature deformation behavior and constitutive modeling for 20CrMnTiH steel. Materials \& Design .57(2014)465-471.

[2] J. Liu, W. Feng, F.J. Xu, Y.H. Fu. Warm Deformation Behavior and Modeling of 20CrMnTiH Steel. Hot working process. 42(2013)77-79. (In Chinese)

[3]R. X. Chai, W. B. Su, C. Guo, F. F. Zhang, Constitutive relationship and microstructure for 20CrMnTiH steel during warm deformation. Mater Sci Eng A. 556(2012)473-478.

[4] S.T. Wu, W. Feng, X.Hu. Constitutive modeling for flow behavior of 20CrMnTiH steel.Ironmaking and Steelmaking. 42(2015)481-488.

[5] W.Feng, F.J. Xu. Microstructure evolution and dynamic recrystallization model of 20CrMnTiH steel during hot compression. Journal of Plasticity Engineering. 21(2014)78-84.

[6] S. S. Zhang, M. Q. Li, Y. G. Liu, J.Luo, T. Q. Liu. The growth behavior of austenite grain in the heating process of 300Mn steel. Mater SciEng A.528(2011)4967-4972.

[7] C.X. Yue, L.W. Zhang, S.L. Liao, H.J. Gao. Mathematical models for predicting the austenite grain size in hot working of GCr15 steel.Comp. Mater. Sci. 45(2009)462-466.

[8] H. Pous-romero, I. Lonardelli, D. Cogswell, H.K.D.H. Bhadeshia.Austenite grain growth in a nuclear pressure vessel steel.Mater SciEngA.567(2013)72-79.

[9] S. J. Lee, Y. K. Lee. Prediction of austenite grain growth during austenitization of low alloy steels. Materials \& Design. 29(2008)1840-1844.

[10] S.C. Kennett, G. Krauss, K.O. Findley. Prior austenite grain size and tempering effects on the dislocation density of low-C Nb-Ti microalloyed lath martensite.Scripta Mater. 107(2015)123-126.

[11] H. S. Yang, H. K. D. H. Bhadeshia. Austenite grain size and the martensite-start temperature.Scripta Mater. 60(2009)493-495.

[12] C. Heinze, A. Pittner, M. Rethmeier, S. S. Babu. Dependency of martensite start temperature on prior austenite grain size and its influence on welding-induced residual stresses. Comp Mater Sci. 69(2013)251-260.

[13] C. M. Sellars, J. A. Whiteman. Recrystallization and grain growth in hot rolling. Metal Sci.13(1979)187-194. 